\title{
Practical Considerations in Providing End-of-Life Care for Dying Patients and Their Family in the Era of COVID-19
}

\author{
Yejin Kim, M.S.W., Shin Hye Yoo, M.D., Ph.D, Jeong Mi Shin, M.D., Hyoung Suk Han, R.N., \\ Jinui Hong, R.N., Hyun Jee Kim, M.S.W.*, Wonho Choi, R.N., Min Sun Kim, M.D. ${ }^{\dagger}$, \\ Hye Yoon Park, M.D., Ph.D. ${ }^{\dagger}$ and Bhumsuk Keam, M.D., Ph.D. ${ }^{\S}$ \\ Center for Palliative Care and Clinical Ethics, Departments of *Social Work, ${ }^{\dagger}$ Pediatrics, \\ ${ }^{\ddagger}$ Psychiatry and ${ }^{\S}$ Internal Medicine, Seoul National University Hospital, Seoul, Korea
}

In the era of coronavirus disease 2019 (COVID-19), social distancing and strict visitation policies at hospitals have made it difficult for medical staff to provide high-quality endof-life (EOL) care to dying patients and their families. There are various issues related to EOL care, including psychological problems of patients and their families, difficulties in EOL decision-making, the complicated grief of the bereaved family, moral distress, and exhaustion of medical staff. In relation to these issues, we aimed to discuss practical considerations in providing high-quality EOL care in the COVID-19 pandemic. First, medical staff should discuss advance care planning as early as possible and use the parallel planning strategy. Second, medical staff should play a role in facilitating patient-family communication. Third, medical staff should actively and proactively evaluate and alleviate dying patients' symptoms using non-verbal communication. Lastly, medical staff should provide care for family members of the dying patient, who may be particularly vulnerable to postbereavement problems in the COVID-19 era. Establishing a system of screening highrisk individuals for complicated grief and connecting them to bereavement support services might be considered. Despite the challenging and limited environment, providing EOL care is essential for patients to die with dignity in peace and for the remaining family to return to life after the loved one's death. Efforts considering the practical issues faced by all medical staff and healthcare institutions caring for dying patients should be made.

Key Words: COVID-19, Terminal care, Death, Palliative care, Advance care planning, Bereavement
Received November 9, 2020

Revised January 4, 2021

Accepted January 4, 2021

\section{Correspondence to}

Shin Hye Yoo

ORCID:

https://orcid.org/0000-0001-7473-1082

E-mail: ifi1024@gmail.com

This research was supported by a grant of the Korea Health Technology R\&D Project through the Korea Health Industry Development Institute (KHIDI), funded by the Ministry of Health \& Welfare, Republic of Korea (grant number : HI20C1995, HC20C0005).

\section{INTRODUCTION}

Since the first patient infected with coronavirus disease 2019 (hereinafter COVID-19) was identified in Wuhan, China, in December 2019, and COVID-19 was recognized as a novel infectious disease [1], there have been over 157 million cumulative confirmed cases and nearly 3.28 million deaths attributed to COVID-19 (as of May 11, 2021, WHO Situation Reports [2]); as such, COVID-19 has posed a steadily increasing burden throughout the world. Various levels of social distancing measures have been implemented worldwide in an effort to respond to the crisis and prevent the spread of infection, and hospitals have also enforced strict visitation policies for the safety of patients, families, and medical staff, such as limiting 
visitors to one person at a time or completely prohibiting visits $[3,4]$. However, despite these restrictions, the number of deaths from COVID-19 continues to increase, and patients without COVID-19 have been succumbing to death in the midst of the public health crisis.

In the United States and many countries in Europe that have also had a significant number of COVID-19-related deaths, discussions on end-of-life care, encompassing advance care planning and palliative care approaches, are well underway [5-7]. In contrast, there have been relatively few COVID-19 deaths in South Korea, and thus, there have been few discussions on end-of-life care for COVID-19 patients. Furthermore, it is not known how the COVID-19 pandemic has affected the end-of-life care of dying patients both quantitatively and qualitatively.

Several problems are expected with regard to end-of-life care for dying patients during the COVID-19 pandemic [8]. Patients may experience emotional problems such as anxiety and depression because they cannot receive support from their families due to visitation restrictions and may have difficulty in making decisions [9]. In turn, families may feel anxious or guilty for not directly participating in end-of-life care and experience difficulty in making decisions without seeing the patients, and it is also difficult for them to receive help from other members of their support systems due to social distancing $[5,10,11]$. As most medical institutions require COVID-19 screening tests before hospitalization, even patients facing imminent death must be tested without exception, and patients and their families in turmoil are forced to spend their valuable last moments locating and visiting designated COVID-19 test centers [12]. Furthermore, the medical staff may also experience feelings of guilt and moral distress as the parties who directly limit visits and due to the failure to provide adequate end-of-life care in the midst of the COVID-19 pandemic [11,13].

Even in the special circumstances of the pandemic, patients must be able to die with dignity and in comfort and receive end-of-life care in order to obtain overall pain relief and spend meaningful time with their families [14,15]. The role of medical staff in the end-of-life care of dying patients is of particular importance in the current situation where caregiving by family is greatly limited due to visitation restrictions and social distancing $[8,16]$. A palliative care team at a medical institution is supposed to provide specialized services, including end-of-life care and bereavement support for some patients and their families, as well as terminally ill cancer patients; however, in practice, it is impossible to provide end-of-life care to all dying patients and their families. Therefore, we present practical considerations for medical staff, who play a key role in end-of-life care, to directly provide high-quality end-of-life care in the front line to dying patients and their families, while taking into account the special circumstances of the COVID-19 pandemic.

\section{BODY}

First, advance care planning refers to making treatment decisions in advance that sufficiently reflect patient's values, thoughts, and wishes $[11,17,18]$, and it has become essential to specify these in writing in a legal document since the enforcement of the Life-Sustaining Treatment Determination Act in February 2018 [19]. Advance care planning is a very important element of end-of-life care, and medical staff need to start discussions with patients and their families as early as possible so that it is not rushed at the last minute [15]; thus, the strategy of parallel planning is recommended. In Korea, advance care planning has been centered on patients with cancer, in whom it is relatively easy to judge whether they are in the terminal stage. In contrast, for diseases that mainly require acutestage treatment, it may be difficult to suddenly shift the focus from immediate treatment to end-of-life care, and it is necessary to have regular discussions with the patient and family for a timely transition of the treatment goal $[7,20,21]$. However, in the era of COVID-19, due to restrictions on family meetings and patient-family communication, the decision-making process may be delayed, or it may be difficult to sufficiently reflect the patient's values and thoughts. Therefore, it is especially important to initiate the goal-of-care discussion as early as possible to determine the goal of caregiving and advance care planning. For patients who are highly likely to receive intensive care due to the characteristics of the disease and patients with high medical uncertainties about the prognosis, parallel planning from an early stage is recommended instead of urgently changing treatment targets near the end of life [11]. Parallel 
planning refers to an approach to discussing options for various potential outcomes when the prognosis is uncertain [22]. Parallel planning in the area of palliative care is "establishing a strategy of hoping for the best but preparing for the worst; that is, making a plan considering not only the possibility of survival but also the possibility of the disease worsening, leading to death." The concept of parallel planning has been used in advance care planning for children or young patients [18,22,23], and it can be applied in situations where discussions should be held early during the COVID-19 pandemic.

Second, in the era of COVID-19, medical staff can play an important role as the only facilitators of patient-family communication in the hospital. Good communication is a prerequisite for psychosocial support for patients and their families and for integrated holistic care [5]. However, due to restrictions on visits to patients in the COVID-19 pandemic, the opportunity for patient-family communication has been significantly reduced. Under these circumstances, medical staff can serve as direct intermediaries between the patient and family to promote meaningful communication between them or aid in communication. In the latter case, they should advise and guide the patients and families to help them achieve meaningful communication even in limited circumstances, create an environment for communication using non-face-to-face means [11], and establish a system that can support patientfamily communication at each site (Table 1). This type of support from medical staff takes greater importance in environ- ments where visits to patients are completely restricted, such as intensive care units and quarantine wards [5].

Third, pain relief of dying patients is the most crucial aspect of end-of-life care, and medical staff should take more initiative and proactively evaluate and intervene to address physical and mental symptoms. In end-of-life care, it is essential to discontinue treatment and medication that do not help improve symptoms and alleviate pain and to provide medical care centered on the management of uncomfortable symptoms felt by patients [15]. However, in the era of COVID-19, as family members cannot remain near a dying patient, there may be no one to observe and report the patient's symptoms, and smooth communication between the patient and the medical staff may be hampered by wearing personal protective equipment [11]. Therefore, medical staff should take a more active and proactive attitude in evaluating patients' uncomfortable symptoms such as pain and shortness of breath in consideration of these limitations, and they also need to closely observe nonverbal expressions and utilize them in the evaluation.

Finally, medical staff should provide care for patients' families, taking into account that families of dying patients in the COVID-19 pandemic may be more vulnerable to problems that may arise after bereavement. In general, it is known that factors such as a psychiatric history, lack of social support, sudden or traumatic death, unpreparedness for death, death during hospitalization, and death in intensive care units increase the risk of complicated grief of bereaved families of dy-

Table 1. The Roles of Medical Staff in Facilitating Communications between Patients and Families in the Era of the COVID-19 Pandemic and Specific Examples of Content.

\begin{tabular}{|c|c|}
\hline Role of medical staff & Content (examples) \\
\hline Mediating directly between patients and families & $\begin{array}{l}\text { Informing the family of the patient's condition in detail vividly } \\
\text { Telling what the patient wants to say, feel and express to the family } \\
\text { Conveying a message that the family wants to say to the patient } \\
\text { Delivering mementos, messages, letters, voice recording files, etc. that are meaningful to the } \\
\text { patients }\end{array}$ \\
\hline $\begin{array}{l}\text { Leading meaningful communication between patient and } \\
\text { families }\end{array}$ & $\begin{array}{l}\text { Structuring communication } \\
\text { Guiding the family on how to talk to a weak or unconscious patient when visiting } \\
\text { Training and helping the family to do non-face-to-face communication methods and skills } \\
\text { Providing educational materials on dying and death (e.g., a bereavement preparation guide) }\end{array}$ \\
\hline $\begin{array}{l}\text { Setting up an environment using virtual communication } \\
\text { methods }\end{array}$ & Preparing virtual devices such as a mobile phones and tablet PCs \\
\hline $\begin{array}{l}\text { Establishing a patient-family communication support } \\
\text { system in the clinical setting }\end{array}$ & $\begin{array}{l}\text { Training and educating medical staff } \\
\text { Distributing personnel and clarifying the role of each staff in end-of-life care }\end{array}$ \\
\hline
\end{tabular}


ing patients [5]. As is also the case for patients who die in the intensive care unit $[5,13]$, the families of dying patients in the era of COVID-19 may feel guilty for not directly participating in the end-of-life care, experience a psychological burden and regret for decisions made without seeing the patients in person, and have anxiety and fear when thinking of the loneliness and pain the patients may have gone through. In addition, they may feel psychological pain as they are not allowed to perform rituals related to death that have been traditionally performed, and the process of letting go of loved ones can be a traumatic experience $[5,10]$. This can lead to serious psycho-emotional problems such as prolonged grief, which refers to physical and psychiatric dysfunctional symptoms observed in bereaved family members who have difficulties controlling their depression, anxiety, and sadness after bereavement $[5,9,10]$. Therefore, all medical staff providing care for dying patients should communicate with appropriate consideration of the psychosocial aspects that the families of dying patients may face, especially in the situation where the patient and the family cannot be together in the era of COVID-19. Furthermore, at the medical institution level, a support system should be established to identify family members with a high risk of complicated grief after bereavement and to refer family members to mental health medical treatment, bereavement management counseling, bereavement family gatherings, and social welfare support services.

\section{CONCLUSIONS AND SUGGESTIONS}

It is quite challenging to provide quality end-of-life care in the era of COVID-19, but doing so can help patients die comfortably with dignity even in these unusual, limited circumstances. End-of-life care is a valuable service for remaining family members to deal with sadness in a healthy way and live their lives again.

Medical staff are the only people upon whom patients and their families can rely in the unexpected COVID-19 pandemic, and the quality of end-of-life care depends on the capabilities and attitudes of the medical staff. For high-quality end-of-life care, sufficient education must be provided to medical staff, which should be preceded by the establishment of a system and environment conducive to the provision of good end-of- life care. To this end, medical institutions and health authorities should prepare measures to protect and support medical staff so that they can provide high-quality end-of-life care in the clinical field without experiencing burnout even in the era of COVID-19.

\section{CONFLICT OF INTEREST}

No potential conflict of interest relevant to this article was reported.

\section{ORCID}

Yejin Kim, https://orcid.org/0000-0002-1479-3385

Shin Hye Yoo, https://orcid.org/0000-0001-7473-1082

Jeong Mi Shin, https://orcid.org/0000-0003-4556-1242

Hyoung Suk Han, https://orcid.org/0000-0001-6666-6962

Jinui Hong, https://orcid.org/0000-0001-6364-1612

Hyun Jee Kim, https://orcid.org/0000-0001-8060-280X

Wonho Choi, https://orcid.org/0000-0002-7756-4491

Min Sun Kim, https://orcid.org/0000-0001-5323-9857

Hye Yoon Park, https://orcid.org/0000-0003-4114-5102

Bhumsuk Keam, https://orcid.org/0000-0001-8196-4247

\section{AUTHOR'S CONTRIBUTIONS}

Conception or design of the work: YK, SHY. Data collection: YK, SHY, JMS, HSH, JH, HJK. Data analysis and interpretation: YK, SHY. Drafting the article: YK, SHY. Critical revision of the article: YK, SHY, JMS, HSH, JH, HJK, WC, MSK, HYP, BK. Final approval of the version to be published: YK, SHY, JMS, HSH, HJK, JH, WC, MSK, HYP, BK.

\section{SUPPLEMENTARY MATERIALS}

Supplementary materials can be found via https://doi. org/10.14475/jhpc.2021.24.2.130. 


\section{REFERENCES}

1. Huang C, Wang Y, Li X, Ren L, Zhao J, Hu Y, et al. Clinical features of patients infected with 2019 novel coronavirus in Wuhan, China. Lancet 2020;395:497-506.

2. World Health Organization. Number at a glance [Internet]. Geneva: World Health Organization; 2021 [cited 2021 May 11]. Available from: https://www.who.int/emergencies/diseases/novel-coronavirus-2019.

3. Centers for Disease Control and Prevention. Management of visitors to healthcare facilities in the context of COVID-19: Non-US healthcare settings [Internet]. Atlanta, GA: Center for Disease Control and Prevention; 2020 [cited 2020 Sep 15]. Available from: https://www.cdc.gov/ coronavirus/2019-ncov/hcp/non-us-settings/hcf-visitors.html.

4. Lee SM. Total ban on visiting patients in nursing hospitals in the metropolitan area [Internet]. Seoul: Medical News; 2020 [cited 2020 Aug 21]. Available from: http://www.bosa.co.kr/news/articleView.html? idxno=2132747.

5. Morris SE, Moment A, Thomas JD. Caring for bereaved family members during the COVID-19 pandemic: Before and after the death of a patient. J Pain Symptom Manage 2020;60:e70-4.

6. Tahan HM. Essential case management practices amidst the novel coronavirus disease 2019 (COVID-19) crisis: Part 2: End-of-life care, workers' compensation case management, legal and ethical obligations, remote practice, and resilience. Prof Case Manag 2020;25:267-84.

7. Curtis JR, Kross EK, Stapleton RD. The importance of addressing advance care planning and decisions about do-not-resuscitate orders during novel coronavirus 2019 (COVID-19). JAMA 2020;323:1771-2.

8. Yardley S, Rolph M. Death and dying during the pandemic. BMJ 2020;369:m1472.

9. Wallace CL, Wladkowski SP, Gibson A, White P. Grief during the COVID-19 pandemic: Considerations for palliative care providers. J Pain Symptom Manage 2020;60:e70-6.

10. Johns L, Blackburn P, McAuliffe D. COVID-19, Prolonged Grief Disorder and the role of social work. International Social Work 2020;63:6604.

11. Selman LE, Chao D, Sowden R, Marshall S, Chamberlain C, Koffman J. Bereavement support on the frontline of COVID-19: Recommendations for hospital clinicians. J Pain Symptom Manage 2020;60:e81-6.

12. Jeon MO. Emergency room death doubles due to prolonged COVID-19, bereavement trauma for family and medical staff [Internet]. Seoul: Kuki News; 2020 [cited 2020 Sep 19]. Available from: http://www.kukinews.com/newsView/kuk202009180309.

13. Pattison N. End-of-life decisions and care in the midst of a global coronavirus (COVID-19) pandemic. Intensive Crit Care Nurs 2020;58:102862.

14. Chochinov HM, Bolton J, Sareen J. Death, dying, and dignity in the time of the COVID-19 pandemic. J Palliat Med 2020;23:1294-5.

15. Shin J, Chang YJ, Park S-J, Choi JY, Kim S-H, Choi YS, et al. Clinical practice guideline for care in the last days of life. Korean J Hosp Palliat Care 2020;23:103-13.

16. Wang SSY, Teo WZY, Yee CW, Chai YW. Pursuing a good death in the time of COVID-19. J Palliat Med 2020;23:754-5.

17. Brinkman-Stoppelenburg A, Rietjens JA, van der Heide A. The effects of advance care planning on end-of-life care: a systematic review. Palliat Med 2014;28:1000-25.

18. Jack BA, Mitchell TK, O'Brien MR, Silverio SA, Knighting K. A qualitative study of health care professionals' views and experiences of paediatric advance care planning. BMC Palliat Care 2018;17:93.

19. Ministry of Government Legislation. Act on decisions on life-sustaining treatment for patients in hospice and palliative care or at the end of life. Sejong: Ministry of Government Legislation; 2016.

20. Ghosh D, Gupta B. End-of-life issues in the era of the COVID-19 pandemic. Korean J Hosp Palliat Care 2020;23:162-5.

21. Ufere NN, Donlan J, Waldman L, Dienstag JL, Friedman LS, Corey KE, et al. Barriers to use of palliative care and advance care planning discussions for patients with end-stage liver disease. Clin Gastroenterol Hepatol 2019;17:2592-9.

22. Sidgwick P, Fraser J, Fortune PM, McCulloch R. Parallel planning and the paediatric critical care patient. Arch Dis Child 2019;104:994-7.

23. National Guideline Alliance (Great Britain). End of life care for infants, children and young people with life-limiting conditions: planning and management [Internet]. [Place of publication not identified] : National Institute for Health and Care Excellence (UK); 2016 [cited 2016 Dec 7]. Available from: https://www.nice.org.uk/guidance/ng61/resources/end-of-life-care-for-infants-children-and-young-people-withlifelimiting-conditions-planning-and-management-pdf-1837568722885. 